\title{
AN ADAPTATION OF THE NITROUS OXIDE METHOD TO THE STUDY OF THE CEREBRAL CIRCULATION IN CHILDREN; NORMAL VALUES FOR CEREBRAL BLOOD FLOW AND CEREBRAL METABOLIC RATE IN CHILDHOOD ${ }^{1}$
}

\author{
BY CHARLES KENNEDY 2 AND LOUIS SOKOLOFF 3 \\ (From the Children's Hospital of Philadelphia, The Departments of Pediatrics and Neurology, \\ School of Medicine, and the Department of Physiology and Pharmacology, \\ Graduate School of Medicine, University of Pennsylvania, \\ Philadelphia, Penna.)
}

(Submitted for publication November 20, 1956; accepted March 28, 1957)

The nitrous oxide method for determining cerebral blood flow as originally described by Kety and Schmidt (1) has been unsuitable for use in children because of the fairly large amounts of blood withdrawn in its performance and because of its requirement of a greater degree of active cooperation than can be expected from most children under the circumstances of the procedure. Although the integrated sample modification of Scheinberg and Stead (2) permits a considerable reduction in the amount of blood drawn, it loses a valuable check on potential errors arising from defects in the respiratory system or the presence of extracerebral contamination of the internal jugular venous blood. Furthermore, timing and dilution problems associated with the Scheinberg modification lead to errors unless extensive precautions are taken (3). Recently, Baird and Garfunkel (4) have employed a modification of the original method in studies of the cerebral blood flow in infants and children. Blood requirements were reduced by the use of micro-gas analytical techniques $(5,6)$, but the necessary cooperation was achieved only by sedation with barbiturates. Although these drugs, in semi-narcotic doses, have been shown to be without effect on the cerebral circulation and oxygen consumption in adults (7), this has not been established in children. When anesthetic doses are employed, a marked reduction in cerebral oxygen consumption has been observed

\footnotetext{
1 This investigation was supported by research grants from Playtex Park Research Institute, the Kirby McCarthy Fund, and United Cerebral Palsy.

${ }^{2}$ Life Insurance Medical Research Fund Fellow 195153.

3 Present Address : National Institute of Mental Health, Bethesda, Maryland.
}

despite a slight increase in cerebral blood flow (8), the latter change probably a secondary effect of respiratory depression and consequent elevation of blood carbon dioxide tension (9). It is diffcult to estimate the extent to which the Baird and Garfunkel method (4) is influenced by the sedation, inasmuch as neither the doses of barbiturates nor the values for blood carbon dioxide tension are reported.

The present communication describes a modification of the original method which is suitable for use without sedation in normal children. To test its validity it has been applied to a group of normal young men for which comparative values obtained with the original technique are available. Values are then presented for cerebral blood flow (CBF), cerebral oxygen consumption $\left(\mathrm{CMRO}_{2}\right)$ and cerebral vascular resistance (CVR) in normal children.

\section{METHOD}

The changes in the classical procedure were directed along two lines: 1) reduction in the amount of blood drawn, and 2) achieving active cooperation of the child by minimizing discomfort and anxiety.

Reduction in the amount of blood drawn. A micro method was developed for the determination of nitrous oxide in blood (10) which permitted the measurement of nitrous oxide content in $0.2 \mathrm{ml}$. of blood and reduced the total requirement for the estimation of cerebral blood flow to $11 \mathrm{ml}$. To permit replicate determinations, the actual volume of the blood samples was reduced only to $1 \mathrm{ml}$., but this reduction was sufficient to greatly enhance the importance of dead space in the sampling system as a source of error. Therefore, the multiple sampling manifold and the standard luer connections of the original technique were not employed. Small bore plastic tubing

\footnotetext{
4 "Tygon" (I.D. $0.034 " \times$ O.D. 0.050") was supplied by U. S. Stoneware Co., Akron, Ohio.
} 


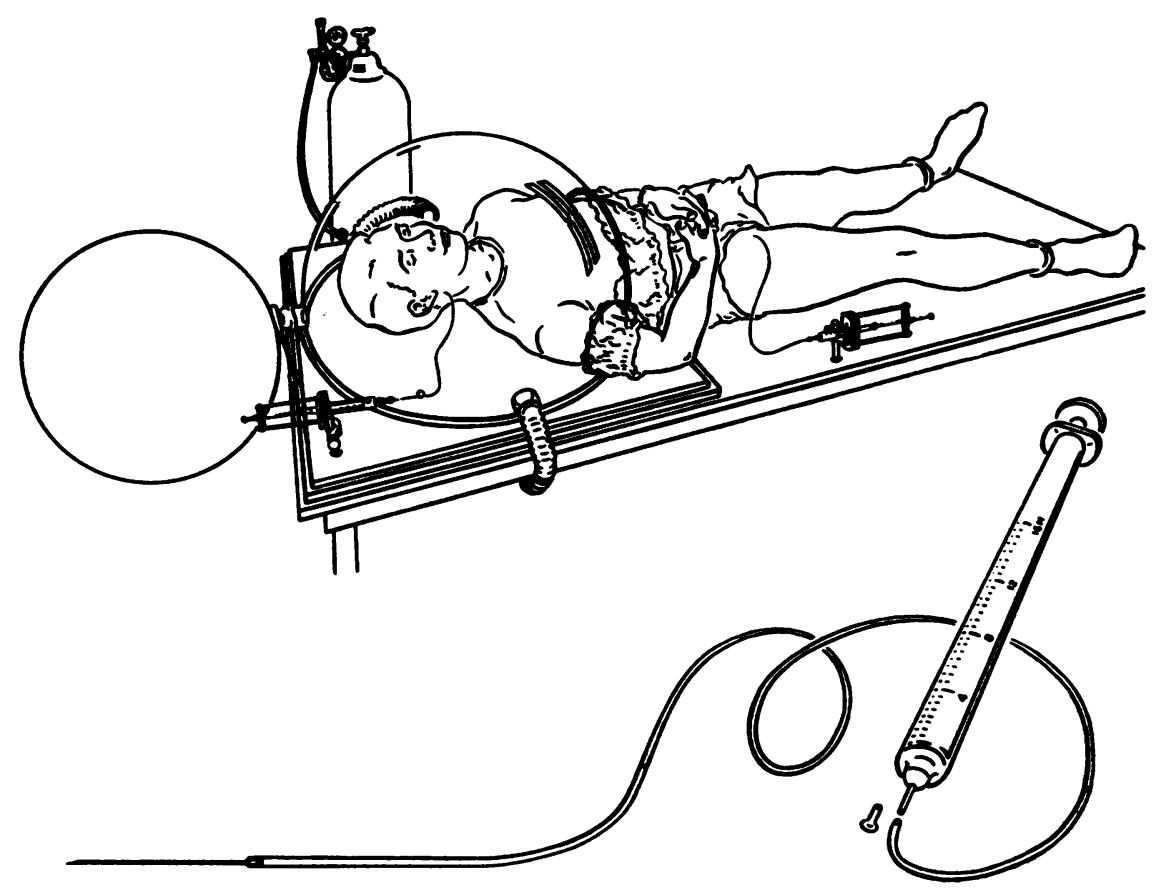

Fig. 1. Apparatus Used in the Determination of Cerebral Blood Flow in Chimdren

was attached directly to hub-free needles, the other end being interchangeably connected to modified $1-\mathrm{ml}$. tuberculin syringes. Number 20 gauge stainless steel tubing, $1 \mathrm{~cm}$. in length, was sealed into the glass tips of the latter, thereby reducing their dead space to approximately $0.01 \mathrm{ml}$. (Figure 1).

Achieving cooperation. To avoid the anxiety associated with the use of an anesthesia mask, a transparent acrylic plastic hemisphere, 24 inches in diameter, ${ }^{\circ}$ was used to administer the nitrous oxide air mixture. This permitted the child to watch motion pictures projected upon the ceiling before and during the test period. To minimize pain in establishing the sampling systems, meticulously sharpened No. 23 gauge needles were used, the bores of which were polished ${ }^{6}$ and coated with a silicone solution ${ }^{7}$ to prevent clotting.

The actual procedure was as follows: After the child had become familiar with the apparatus and the details of the procedure, he was placed on a table covered with a hard mattress. The legs were immobilized with elastic bandages on a suitable board. The femoral artery puncture was performed in the usual aseptic manner using the needle with sterile tubing attached (Figure 1) after in-

\footnotetext{
5 Made by Farquhar Transparent Globes, Philadelphia, $\mathrm{Pa}$.

6 This was done by using an aqueous suspension of gamma alumina with rapid alternating movements of a 3-0 nylon suture threaded through the needle bore.

7 "Desicote" supplied by Beckman Instrument Co.
}

filtrating the superficial layers of the skin with a small amount of 1 per cent procaine. The other end of the tubing was then connected to a 5-ml. syringe pipette filled with dilute heparin solution ( $2 \mathrm{mg}$. per $\mathrm{ml}$.). After blood had been allowed to flow into the syringe to clear the system of air bubbles, heparin solution was flushed through the tubing and needle by twisting the volume control screw of the syringe pipette. Occasional quarter turns of the latter served to prevent backflow of blood into the needle. The puncture of the superior bulb of the internal jugular vein was carried out in the usual manner $(11,12)$ with the hub-free needle and attached plastic tubing (Figure 1). Heparin solution was introduced into the system as described for the femoral arterial puncture. The length of the needle selected varied between $11 / 2$ and 2 inches and was chosen according to the size of the child so that there was the shortest possible length protruding beyond the surface of the skin once it was properly in place. This allowed free movement of the head and neck without risking its displacement. After the sampling systems had been established and flushed with heparin solution, the dome was placed over the head and shoulders, and plastic sheeting, glued to its free edge, was tucked in tightly around the trunk. When used with adults, it was more comfortable for the subject to have arm ports provided in the hemisphere so that the hands might rest folded on the abdomen. Until the start of the test period, the dome was supported with a prop at the upper end, and an electric fan circulated air through the opened chamber. 
TABLE I

Gas content, $\mathrm{pH}$ and $\mathrm{pCO}_{2}$ of arterial blood before and $6^{\prime}-8^{\prime}$ after enclosure in dome *

IIIS roun atis

\begin{tabular}{|c|c|c|c|c|c|}
\hline & $\begin{array}{c}\text { I } \\
\text { Maen Values } \\
\text { Before }\end{array}$ & $\begin{array}{c}\text { II } \\
\text { Lean Values } \\
61-81\end{array}$ & $\begin{array}{l}\text { II - I } \\
\text { Mean } \\
\text { Difference }\end{array}$ & $\begin{array}{l}\text { Standard } \\
\text { Bros Differnese }\end{array}$ & ensimet \\
\hline $\mathrm{CO}_{2}$ content & 50.532 & 50.031 & -0.502 & \pm 0.40 & $>0.2$ \\
\hline ph . & 7.408 & 7.403 & +0.001 & \pm 0.005 & $>0.7$ \\
\hline $\mathrm{pCO}_{2}$ & 43.0 & 42.6 & -0.4 & \pm 0.4 & 20.3 \\
\hline
\end{tabular}

Exres crunger

\begin{tabular}{lccccc}
$\mathrm{CO}_{2}$ content & 47.003 & 47.960 & +0.17 & \pm 0.47 & $>0.6$ \\
$\mathrm{pH}$ & 7.375 & 7.382 & +0.006 & \pm 0.005 & $>0.2$ \\
$\mathrm{pCO}_{2}$ & 42.7 & 42.5 & -0.2 & \pm 0.4 & $>0.6$ \\
\hline
\end{tabular}

- Ventilated with air at 20 - 30 11ters/mimute.

- As deternined by the sethod of patred comparlsons.

A weather balloon, 8 filled to 3 feet in diameter with the usual gas mixture (15 per cent nitrous oxide, 21 per cent oxygen, and 64 per cent nitrogen) and clamped at the neck with an intestinal clamp, was connected to the dome over an opening $11 / 2$ inches in diameter. After withdrawal of a blood sample to be used as the blank for the nitrous oxide analyses, the dome was lowered, and the balloon clamp released to permit a rapid washout of the air in the dome. Simultaneously, drawing of the integrated first minute samples of arterial and cerebral venous blood was begun, the rate being $0.25 \mathrm{ml}$. every fifteen seconds. Before the balloon had become completely deflated, a tank containing the gas mixture, and connected to the dome by a rubber hose, was turned on at the rate of 20 to 30 liters per min. The number and timing of subsequent samples were the same as in the original method except that each was taken over a somewhat shorter interval, i.e., 10 to 15 seconds. Before the withdrawal of each blood sample, the tubing was first filled with fresh blood by drawing back the barrel of the heparin containing syringe. All sample syringes were capped and kept in ice water until analyzed. The calculation of cerebral blood flow was done as originally described after plotting the nitrous oxide concentrations of the arterial and jugular venous blood against time (1).

In the studies reported here, in which the above procedure was used, estimations of cerebral oxygen consumption, cerebral respiratory quotient, and blood carbon dioxide tension were calculated in the usual manner and required the measurement of the appropriate blood

8 Supplied by Seyfang Laboratories, Atlantic City, New Jersey. constituents. Blood oxygen and carbon dioxide contents were determined by the manometric technique of Van Slyke and Neill (13) as modified by Kety (14). Hemoglobin was estimated as cyanmethemoglobin (15) in a Klett-Summerson photometer using the copper sulfate standard (16). Blood pH was measured at ambient temperature by means of a Cambridge $\mathrm{pH}$ meter and micro glass electrode and corrected to $37^{\circ} \mathrm{C}$. by the factors of Rosenthal (17). Blood carbon dioxide tension was computed by means of the nomogram of Peters and Van Slyke (18).

The modified method for CBF determination was tested on a group of normal, young male university students drawn from the same population previously studied by one of us (19). The children studied by this technique included five boys and four girls between the ages of 3 and 11 years. This was a highly selected group of the most cooperative children. Thirty-five others were originally selected for the procedure, but at one stage or another in the preparation (usually just before the needle punctures) became uncooperative. The two 3-year-old children required some restraint at the time of the needle punctures, but thereafter one went to sleep and the other was content to lie quietly. The past medical history of the children was negative for central nervous system disease, except for occasional headaches in two (J.H. and R.G.), and two febrile convulsions in one (M.C.). The latter had had one such convulsion two months prior to the study but no recurrence subsequently over a three-year period. At the time of this writing she was well and free of any signs of any central nervous system disorder. 


\section{RESULTS}

The large volume of dead space in the respiratory system employed in the modified technique suggested the possibility of alterations in blood gas tensions, particularly $\mathrm{CO}_{2}$ tension, which might alter cerebral blood flow (9). Therefore, arterial $\mathrm{CO}_{2}$ content, $\mathrm{pH}$, and $\mathrm{pCO}_{2}$ were determined in nine adults and eleven children while breathing room air and 6 to 8 minutes after being enclosed within the plastic dome, which was ventilated with the nitrous oxide air mixture at the rate of 20 to 30 liters per minute, the rate employed in the cerebral blood flow studies. As can be seen from Table I, no significant changes were observed. Also, three additional experiments were performed (two adults and one child) in which the carbon dioxide concentration in the inspired air in the dome was determined by the method of Scholander (20) after the subjects' enclosure within it, the conditions being identical with those of the cerebral blood flow studies. In these, the carbon dioxide concentration was found to rise to $0.4,0.5$, and 0.3 per cent, respectively, none of these values approaching the 2.5 per cent level which Patterson, Heyman, Battey, and Ferguson (21) have found to be the threshold for alteration of cerebral blood flow.

Data on blood constituents and the cerebral circulatory functions obtained with the modified method are tabulated in Tables II and III, respectively. The results obtained in the children are individually tabulated; only the mean values and standard errors obtained in normal young men are presented for comparison. It is apparent from the latter values that the modified technique yields values for cerebral circulatory and metabolic functions comparable to those obtained with the original method (1). Thus, cerebral blood flow, vascular resistance, arteriovenous oxygen difference, and respiratory quotient did not differ significantly from the values reported by Kety and Schmidt in a similar group of subjects (1). Only the cerebral oxygen consumption, $4.2 \mathrm{ml}$. oxygen per $100 \mathrm{Gm}$. per min., obtained with the modified technique differed significantly from the originally reported value (1), statistically significantly exceeding the value $3.3 \mathrm{ml}$. oxygen per 100 Gm. per min. reported by Kety and Schmidt ( $p<$ 0.02 ).

Comparison of the results obtained in the children and the young adults reveals some notable differences. The differences found in pulse rate, blood pressure, hemoglobin concentration, blood gas concentrations, and blood $\mathrm{pH}$ were all to be expected in view of the established normal values for children $(22,23)$. The mean cerebral blood flow in children, $106 \mathrm{ml}$. per $100 \mathrm{Gm}$. per min., was found to be considerably greater than the mean

TABLE II

Blood constituents in children and adults using the modified technique

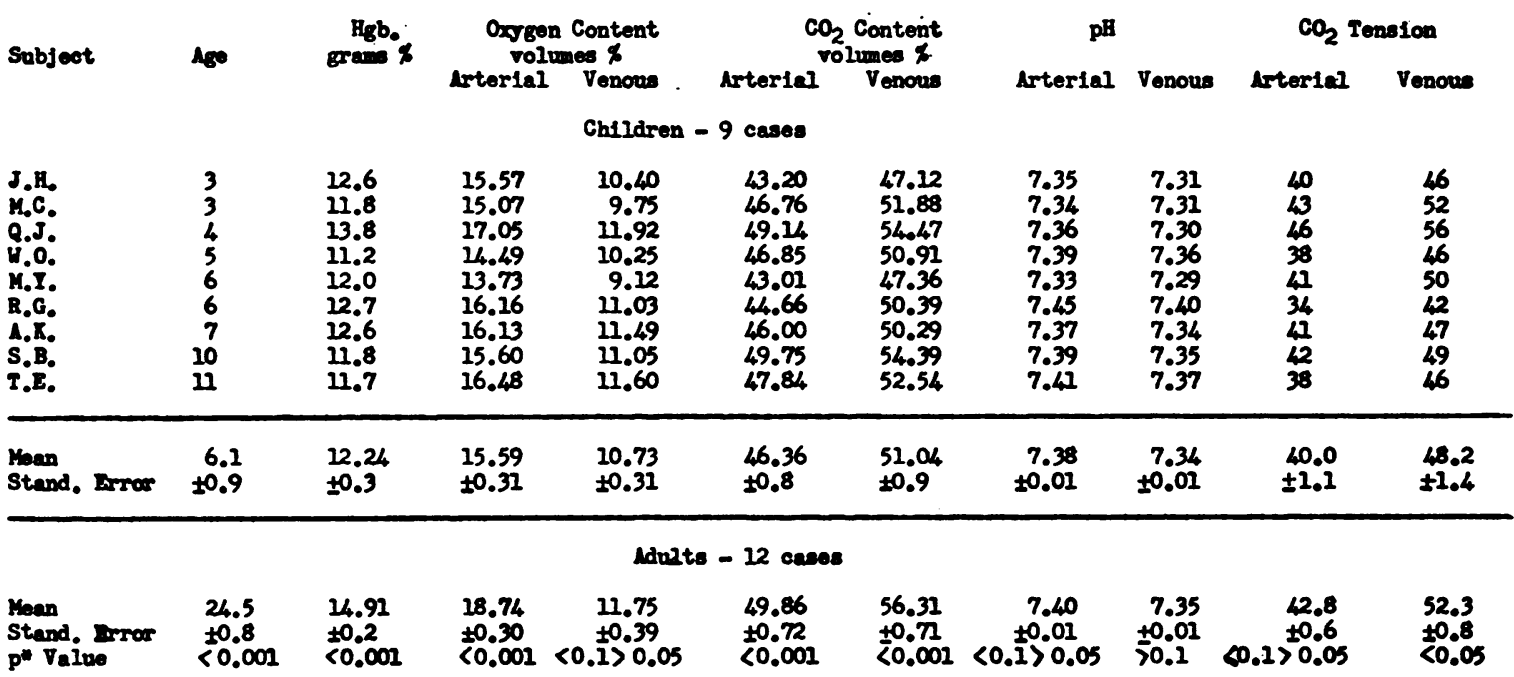


TABLE III

Comparison of data on cerebral circulatory functions in children and adults using the modified technique

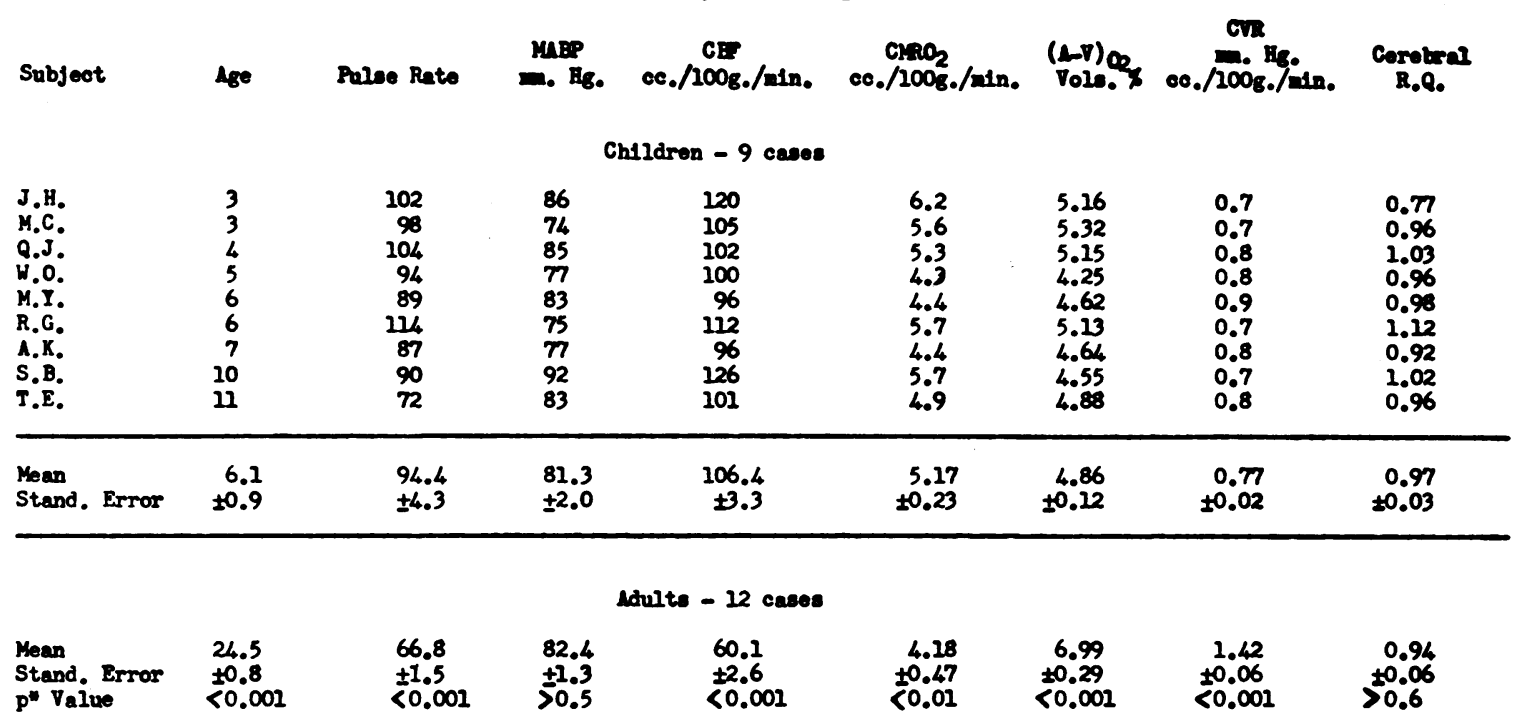

- Determined by the method of estimating the significance of the difference between two moans.

value, $60 \mathrm{ml}$. per $100 \mathrm{Gm}$. per min., observed in the young adults $(p<0.001)$. Also significantly higher in children was the cerebral oxygen consumption, the mean value being $5.2 \mathrm{ml}$. per $100 \mathrm{Gm}$. per min. as compared to $4.2 \mathrm{ml}$. per $100 \mathrm{Gm}$. per min. in the adults $(p<0.01)$. The cerebral vascular resistance in the children was $0.8 \mathrm{~mm}$. $\mathrm{Hg}$ per $100 \mathrm{Gm}$. per min., which was statistically significantly lower than the $1.4 \mathrm{~mm}$. $\mathrm{Hg}$ per $100 \mathrm{Gm}$. per min. observed in young adults $(\mathrm{p}<0.001)$. No difference in the cerebral respiratory quotient (R.Q.) between the two groups was observed.

The results of repeated determinations of CBF, $\mathrm{CMRO}_{2}$ and $\mathrm{CVR}$ in a single child using the modified method are seen in Table IV. The differences reflect not only the errors of the method but also, no doubt, some degree of physiological variation. The variability is comparable to that reported with the original procedure (24).

\section{DISCUSSION}

The modified method for measuring cerebral blood flow was found to yield values for $\mathrm{CBF}$ in normal young men comparable to those of the original technique, but the calculated mean values for $\mathrm{CMRO}_{2}$ were found to be significantly higher. Some evidence exists that anxiety may cause an increase in $\mathrm{CMRO}_{2}$ (25), but we have no reason to suspect that there was any difference in the degree of anxiety present in the two groups of young men. The discrepancy between the two methods with respect to $\mathrm{CMRO}_{2}$ remains unexplained as do also similar differences in results obtained with other variations of the original method (26). Indeed, one of us (L.S.) has recently completed a series in normal young adults studied by the original techniques without modification in which the values for $\mathrm{CBF}$ and $\mathrm{CMRO}_{2}$ are comparable to the adult values reported here (27).

The possibility that the higher values for CBF and $\mathrm{CMRO}_{2}$ found in the children may have resulted from specific conditions of the procedure must be considered. In view of the report of Schmidt and Hendrix (28) that light stimulation of the retina results in an increase in blood flow to the visual cortex in cats, the projection of motion pictures, not done for the adults, might be considered of importance in accounting for the higher $\mathrm{CBF}$ in the children. However, the authors of this study indicate that the increase in $\mathrm{CBF}$ was confined only to a small, sharply demarcated area, and, therefore, it is unlikely that, even if such an increase occurred it would have a measurable effect on over-all cerebral blood flow. 
Furthermore, the studies in the children were conducted in a dimly lighted room in order that the picture, reflected from the painted ceiling, could be seen, and, therefore, there was probably no greater visual stimulation in this group than in the adults. The films chosen were of vacuous content, but of sufficient interest to hold a child's attention without inducing anxiety. It is doubtful that they were provocative of cerebration of comparable intensity to that required in solving arithmetic problems, a form of mental activity which has been shown not to be associated with measurable increases in $\mathrm{CBF}$ or $\mathrm{CMRO}_{2}$ (29).

An additional factor which must be considered is the degree of anxiety in the children as compared with that in the adults. Great pains were taken to minimize this, and that it was not a major factor is suggested by mean pulse rate and mean arterial blood pressure readings which are not above the normal resting level for children 6 years of age (23). Also, in the child studied on four separate occasions, there was no suggestion of a decrease in his $\mathrm{CBF}$ and $\mathrm{CMRO}_{2}$ as he became thoroughly familiar with and, therefore, presumably less anxious about the procedure. A subjective evaluation of the subjects was that the children were less anxious than the adults.

Garfunkel, Baird, and Ziegler (30) have reported lower values for $\mathrm{CBF}$ and $\mathrm{CMRO}_{2}$ in children than obtained by us. However, most of the subjects in their series had gross evidence of neurological or mental defects. Current studies in this laboratory (31) indicate that such abnormalities are frequently accompanied by reductions in $\mathrm{CBF}$ and $\mathrm{CMRO}_{2}$. Furthermore, the mean age of their group was 32 months as compared with 6.1 years in our series. Although differences in techniques and their use of sedation make any conclusions only tenuous, their finding of a lower $\mathrm{CMRO}_{2}$ at this much younger age level is consistent with the results of in vitro studies in the rat $(32,33)$ and $\operatorname{dog}(34)$, where $\mathrm{CMRO}_{2}$ was found to be at a lower level in the very young animal.

In view of the high total body metabolic rate in childhood (35), it is, perhaps, to be expected that the cerebral metabolic rate would also be higher than in adult life. However, if this is related to growth, it is surprising to find that $\mathrm{CMRO}_{2}$ remains at a high level after the age

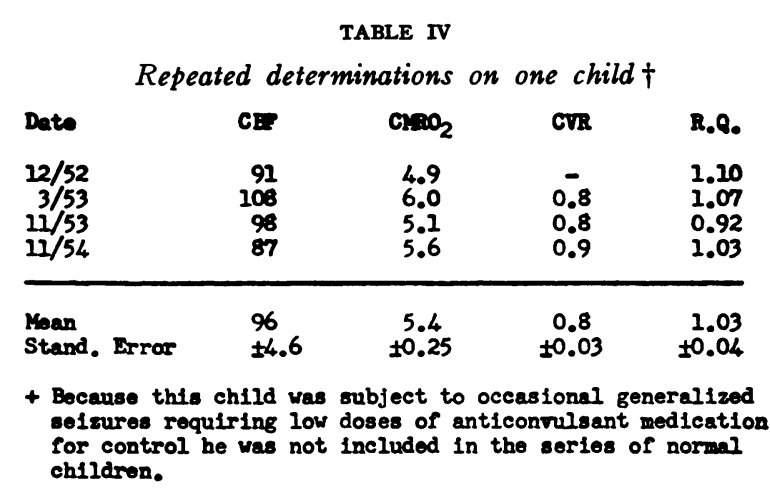

of 6 when the brain has reached 95 per cent of its mature size (36). Furthermore, in contrast to total body metabolic rate, which decreases with advancing age throughout the pre-adolescent years, $\mathrm{CMRO}_{2}$ was found to have no significant correlation either positive or negative with age between the ages of 3 and 10 years $(r=-0.21, p>0.1)$. Indeed, it was found to be relatively constant over that age span. Consistent with this pattern of change in $\mathrm{CMRO}_{2}$ with growth are the in vitro measurements in the rat $(32,33,37)$, which together with our in vivo studies constitute further evidence that the energy requirements for brain tissue are determined independently from the body as a whole (38) and that these are associated with metabolic processes not directly related to increments in brain size. Gordan, Guadagni, Picchi, and Adams (39) have suggested that the steroid hormones may be of considerable importance in the regulation of $\mathrm{CMRO}_{2}$ and that our findings, together with their observations of higher value for $\mathrm{CBF}$ and $\mathrm{CMRO}_{2}$ than normal in testicular eunuchoidism and hypopituitrism, may be related to an inhibitory action of certain of these agents which has been observed in vitro.

Because of the special characteristics of cerebral maturation, a consideration of the high cerebral metabolic rate in childhood leads to an intriguing corollary. For example, it can be calculated $^{\top}$ that in a young child the brain may ac-

\footnotetext{
${ }^{9}$ A normal five-year-old child weighing 20 kilograms has an average metabolic rate of 36 calories per hour (25). Since the caloric value of oxygen is $4.8 \mathrm{cal}$. per liter, the total body oxygen consumption is 7.5 liters per hour or $125 \mathrm{ml}$. per minute, assuming a brain weight at this age of approximately 1200 grams and a $\mathrm{CMRO}_{2}$ of $5.2 \mathrm{ml}$. per $100 \mathrm{Gm}$. per min., the total cerebral oxygen consumption equals $62 \mathrm{ml}$. per min. or half the total body uptake.
} 
count for approximately one-half of the basal total body oxygen consumption. This calculation requires the assumption that the $\mathrm{CMRO}_{2}$ in children in the basal state is not significantly lower than the values reported here, but the assumption is probably justified in view of the several reports of the lack of change in cerebral metabolic rate in conditions in which total body metabolic rate is known to be altered $(19,29,38)$.

\section{SUMMARY}

1. A modification of the original method for measuring cerebral blood flow has been described which is suitable for use in normal children. The results obtained with the modified procedure proved comparable to those derived using the original technique.

2. In a group of normal children the cerebral blood flow and the cerebral metabolic rate were found to be significantly higher than in normal young adults, and the cerebral vascular resistance was significantly lower.

\section{ACKNOWLEDGMENTS}

The authors wish to express their appreciation to Dr. Seymour S. Kety for his helpful suggestions and criticisms. The technical assistance of Miss Harriet Ballard was invaluable.

\section{REFERENCES}

1. Kety, S. S., and Schmidt, C. F., The nitrous oxide method for the quantitative determination of cerebral blood flow in man: theory, procedure and normal values. J. Clin. Invest., 1948, $27,476$.

2. Scheinberg, P., and Stead, E. A., Jr., The cerebral blood flow in male subjects as measured by the nitrous oxide technique. Normal values for blood flow, oxygen utilization, glucose utilization, and peripheral resistance, with observations on the effect of tilting and anxiety. J. Clin. Invest., 1949, 28, 1163.

3. Stroud, M. W., Lambertsen, C. J., Wendel, H., and Daley, M. deB., Comparison of continuous and intermittent sampling in nitrous oxide method for determining cerebral blood flow. Federation Proc., 1954, 13, 147.

4. Baird, H. W., and Garfunkel, J. M., A method for the measurement of cerebral blood flow in infants and children. J. Pediat., 1953, 42, 570.

5. Edwards, G. A., Scholander, P. F., and Roughton, F. J. W., Microgasometric estimation of the blood gases. III. Nitrogen. J. Biol. Chem., 1943, 148, 565.

6. Roughton, F. J. W., and Scholander, P. F., Micro- gasometric estimation of the blood gases. I. Oxygen. J. Biol. Chem., 1943, 148, 541.

7. Kety, S. S., Woodford, R. B., Harmel, M. H., Freyhan, F. A., Appel, K. E., and Schmidt, C. F., Cerebral blood flow and metabolism in schizophrenia. The effects of barbiturate semi-narcosis, insulin coma and electroshock. Am. J. Psychiat., 1948, 104, 765.

8. Wechsler, R. L., Dripps, R. D., and Kety, S. S., Blood flow and oxygen consumption of the human brain during anesthesia produced by thiopental. Anesthesiology, 1951, 12, 308.

9. Kety, S. S., and Schmidt, C. F., The effects of altered arterial tensions of carbon dioxide and oxygen on cerebral blood flow and cerebral oxygen consumption of normal young men. J. Clin. Invest., 1948, 27, 484.

10. Kennedy, C., A micro method for the determination of nitrous oxide in blood. J. Applied Physiol., In press.

11. Myerson, A., Halloran, R. D., and Hirsch, H. L., Technic for obtaining blood from the internal jugular vein and carotid artery. Arch. Neurol. \& Psychiat., 1927, 17, 807.

12. Gibbs, E. L., Lennox, W. G., and Gibbs, F. A., Bilateral internal jugular blood. Comparison of A-V differences, oxygen-dextrose ratios and respiratory quotients. Am. J. Psychiat., 1945, 102, 184.

13. Van Slyke, D. D., and Neill, J. M., The determination of gases in blood and other solutions by vacuum extraction and manometric measurement. I. J. Biol. Chem., 1924, 61, 523.

14. Kety, S. S., Quantitative Determination of Cerebral Blood Flow in Man. Methods in Medical Research I. Chicago, Year Book Publishers, 1948, p. 204.

15. Drabkin, D. L., and Austin, J. H., Spectrophotometric studies. II. Preparations from washed blood cells; nitric oxide hemoglobin and sulfhemoglobin. J. Biol. Chem., 1935, 112, 51.

16. Drabkin, D. L., The standardization of hemoglobin measurement. Am. J. M. Sc., 1948, 215, 110.

17. Rosenthal, T. B., The effect of temperature on the $\mathrm{pH}$ of blood and plasma in vitro. J. Biol. Chem., 1948, 173, 25.

18. Peters, J. A., and Van Slyke, D. D., Quantitative Clinical Chemistry. Vol. II, Methods. Baltimore, Williams \& Wilkins, 1932.

19. Mangold, R., Sokoloff, L., Conner, E., Kleinerman, J., Therman, P. G., and Kety, S. S., The effects of sleep and lack of sleep on the cerebral circulation and metabolism of normal young men. J. Clin. Invest., 1955, 34, 1092.

20. Scholander, P. F., Analyzer for quick estimation of respiratory gases. J. Biol. Chem., 1942, 146, 159.

21. Patterson, J. L., Jr., Heyman, A., Battey, L. L., and Ferguson, R. W., Threshold of response of the cerebral vessels of man to increase in blood carbon dioxide. J. Clin. Invest., 1955, 34, 1957. 
22. Cassels, D. E., and Morse, M., Arterial blood gases and acid-base balance in normal children. $\mathrm{J}$. Clin. Invest., 1953, 32, 824.

23. Nelson, W. E., Ed., Textbook of Pediatrics, 6th ed. Philadelphia, W. B. Saunders Co., 1954.

24. Kety, S. S., Circulation and metabolism of the human brain in health and disease. Am. J. Med., 1950, 8, 205.

25. Sokoloff, L., Relation of cerebral circulation and metabolism to mental activity in Korey, S. R., and Nurnberger, J. I., I. Neurochemistry (Progress in Neurobiology, 1). New York, Hoeber-Harper, 1956, p. 216.

26. Kety, S. S., Changes in cerebral circulation and oxygen consumption which accompany maturation and aging in International Neurochemical Symposium, 1st, Magdalen College, Oxford, 1954, Biochemistry of the Developing Nervous System. New York, Academic Press, 1955, p. 208.

27. Sokoloff, L., Perlin, S., Kornetsky, C., and Kety, S. S., The effects of d-lysergic acid diethylamide on cerebral circulation and over-all metabolism. Ann. New York Acad. Sc., In press.

28. Schmidt, C. F., and Hendrix, J. P., The action of chemical substances on cerebral blood-vessels. A. Research Nerv. \& Ment. Dis., Proc., 1937, 18, 229.

29. Sokoloff, L., Mangold, R., Wechsler, R. L., Kennedy, C., and Kety, S. S., The effect of mental arithmetic on cerebral circulation and metabolism. J. Clin. Invest., 1955, 34, 1101.

30. Garfunkel, J. M., Baird, H. W., and Ziegler, J., The relationship of oxygen consumption to cerebral functional activity. J. Pediat., 1954, 44, 64.
31. Kennedy, C., Cerebral blood flow and oxygen consumption in mentally retarded children, To be published.

32. Himwich, H. E., Baker, Z., and Fazekas, J. F., The respiratory metabolism of infant brain. Am. J. Physiol., 1939, 125, 601.

33. Tyler, D. B., and van Harreveld, A., The respiration of the developing brain. Am. J. Physiol., 1942, $136,600$.

34. Himwich, H. E., and Fazekas, J. F., Comparative studies of the metabolism of the brain of infant and adult dogs. Am. J. Physiol., 1941, 132, 454.

35. Benedict, F. G., and Talbott, F. B., Metabolism and growth from birth to puberty. Washington, D. C., The Carnegie Institution of Washington, 1921, p. 206.

36. White House Conference on Child Health and Protection. Sect. I. Medical Service Committee on Growth and Development. Growth and Development of the Child. Part II. Anatomy and Physiology. New York, Century Press, 1933, p. 180.

37. Donaldson, H. H., and Hatai, S., On the weight of the parts of the brain and on the percentage of water in them according to brain weight and to age, in albino and in wild Norway rats. J. Comp. Neurol., 1931, 53, 263.

38. Sokoloff, L., Wechsler, R. L., Mangold, R., Balls, K., and Kety, S. S., Cerebral blood flow and oxygen consumption in hyperthyroidism before and after treatment. J. Clin. Invest., 1953, 32, 202.

39. Gordan, G. S., Guadagni, N., Picchi, J., and Adams, J. E., Steroid anesthesia in man: clinical and cerebral metabolic effects. J. Internat. Coll. Surgeons, 1956, 25, 9. 